\title{
Science and Technology Networks: A Helping Hand to Boost Implementation of the Sendai Framework for Disaster Risk Reduction 2015-2030?
}

\author{
Robert Šakić Trogrlić $\hat{c}^{1,2,3} \cdot$ Lydia Cumiskey $^{2,3,4} \cdot$ Annisa Triyanti $^{2,5}$. \\ Melanie J. Duncan $^{6}$ - Nuha Eltinay ${ }^{2,7}$ • Rick J. Hogeboom ${ }^{8}$ - Mansi Jasuja, ${ }^{9,10}$ • \\ Chinaporn Meechaiya ${ }^{11} \cdot$ Christina J. Pickering ${ }^{12} \cdot$ Virginia Murray $^{13,14}$
}

Published online: 27 March 2017

(C) The Author(s) 2017. This article is an open access publication

\begin{abstract}
The Sendai Framework for Disaster Risk Reduction 2015-2030 underlines the importance of Science and Technology (S\&T) and S\&T networks for effective disaster risk reduction (DRR). The knowledge of existing S\&T networks and their exact role in DRR, however, is limited. This opinion piece initiates a discussion on the role of S\&T networks in the implementation of the Sendai Framework. The article highlights that current practice is oriented towards a narrative that emphasizes the potential of S\&T for DRR and stresses a collaborative approach delivered through networks. But a true understanding of whether and how S\&T networks can mobilize and enable S\&T for DRR is missing. We call for a review of existing S\&T networks for DRR and the development of good practice guidelines on S\&T networks for DRR. This review should include knowledge on how to overcome
\end{abstract}

Robert Šakić Trogrlić

rs36@hw.ac.uk

1 School of Energy, Geoscience, Infrastructure and Society, Heriot-Watt University, Edinburgh EH14 4AS, UK

2 United Nations Major Group for Children and Youth, 1030 Brussels, Belgium

3 Water Youth Network, 9200 Nanterre, France

4 Flood Hazard Research Centre, Middlesex University, The Burroughs, Hendon, London NW4 4BT, UK

5 Governance and Inclusive Development, Department of Geography, Planning and International Development, University of Amsterdam, 1018 WV Amsterdam, The Netherlands

6 British Geological Survey (Natural Environment Research Council), Lyell Centre, Edinburgh EH14 4AP, UK

7 School of the Built Environment and Architecture, London South Bank University, London SE1 OAA, UK common challenges and maximize the benefits, along with a framework for successful evaluation of such networks. This knowledge would provide much needed guidance for existing and emerging networks.

Keywords Sendai Framework for Disaster Risk Reduction 2015-2030 · Science and Technology $(\mathrm{S} \& \mathrm{~T}) \cdot$ Networks $\cdot$ Disaster risk reduction

\section{Interplay Between Science and Technology, Networks, and Disaster Risk Reduction}

The Sendai Framework for Disaster Risk Reduction 2015-2030 calls for a holistic approach that generates and utilizes knowledge across sectors and disciplines (UNISDR

8 Twente Water Centre, University of Twente, 7500 AE Enschede, The Netherlands

9 Institute for Housing and Urban Development Studies, Alumni International Network, 3062 PA Rotterdam, The Netherlands

10 Royal Dutch Water Network (Koninklijk Nederlands Water netwerk), 2596 AA The Hague, The Netherlands

11 Asian Disaster Preparedness Center (ADPC), Bangkok 10400, Thailand

12 University of Ottawa, Ottawa, ON K1N 6N5, Canada

13 Public Health England, London SE1 8UG, UK

14 United Nations International Strategy for Disaster Reduction (UNISDR) Scientific and Technical Advisory Group (STAG), Geneva, Switzerland 
2015). It is evident that in times of increased uncertainty caused by climatic, environmental, socioeconomic, demographic, and political pressures, disaster risk reduction (DRR) at all levels is imperative. Science and Technology (S\&T) availability is rapidly expanding and its use in DRR is an increasing trend (for example, the use of geoinformatics for participatory hazard and vulnerability mapping). But much work is needed to transform this technology and scientific information into societal contexts. Under the term of science, this article uses the Organisation for Economic Co-operation and Development (OECD) (2007) classification of science that includes natural sciences, engineering and technology, medical and health sciences, agricultural sciences, social sciences, and humanities. S\&T is increasingly recognized as a means of providing evidence for effective DRR strategies, policy development, and decision making (Carabine 2015; UNISDR 2015; Dickinson et al. 2016). The Sendai Framework refers to the term technology 19 times, whereas its predecessor, the Hyogo Framework for Action 2005-2015, mentioned the term three times (UNITAR 2015). The Sendai Framework also recommends that S\&T communities should be mobilized through the coordination of existing networks and scientific research institutions at all levels and in all regions, with the support of the UNISDR Science and Technology Advisory Group (UNISDR 2015, Paragraph $25 \mathrm{~g}$ ). Ultimately, such partnerships and networks help create an evidence base and facilitate practical implementation of measures that can result in reducing disaster risks and losses to lives, and as such contribute to the implementation of the Sendai Framework (UNISDR 2015).

A further stepping stone for the role of S\&T networks in DRR was the UNISDR Science and Technology Conference on the Implementation of the Sendai Framework for Disaster Risk Reduction 2015-2030. This assembly was held in January 2016 and resulted in the UNISDR S\&T Roadmap to 2030 as well as the UNISDR S\&T Partnership (UNISDR 2016). The conference underlined the value of partnerships and networks for initiating multidisciplinary research agendas and fostering the linkage of science, policy, and practice (Aitsi-Selmi et al. 2016; Dickinson et al. 2016). One of the outcomes of the conference was the creation of the United Nations Major Group for Children and Youth (UNMGCY) Young Scientists Platform (YSP) on DRR. The YSP provides a space for professional development, knowledge sharing, and research dissemination among young scientists, as well as S\&T and policy actors (UNMGCY 2015).

It is evident that both the Sendai Framework and the post-Sendai era value S\&T networks. The knowledge and evaluation of existing networks and their role in DRR, however, remains limited (Aitsi-Selmi et al. 2016). We support the principle that networks are a powerful means of facilitating the implementation of the Sendai Framework, and hypothesize that the lack of literature on the role of S\&T networks in DRR is not owing to a lack of networks, but is a consequence of the challenge of capturing and documenting the effectiveness of networks and associated learning. The effectiveness of networks remains emphasized and encouraged in rhetoric, unofficial scientific communication, and post-2015 agendas. But existing knowledge does not offer an evidence base of how S\&T networks for DRR can contribute to implementation of the Sendai Framework (Carabine 2015). Yet a vast amount of literature from other fields (for example, governance, global policy networks, international science partnerships) discusses benefits and challenges of network approaches for solving pressing issues of modern society. We maintain that learning from other fields can benefit existing and emerging networks, partnerships, and platforms in the field of DRR, and can enhance development and sharing of the best S\&T practices. Our opinion piece hopes to initiate discussion and calls for further research on the topic. It is motivated by the authors' direct or indirect involvement in S\&T networks including the YSP. The goal of this short opinion article is to serve as a foundation for increased debate and research into the role of S\&T networks, which would in turn provide much needed guidance for existing and emerging networks.

\section{What are Networks and Why Networks for S\&T in DRR?}

The terms partnerships, networks, and platforms are often ambiguous and used interchangeably (Assens and Courie Lemeur 2016). A common ground between networks is the desire to foster different levels of collaboration, cooperation, and coordination (Himmelman 1996). We use the term "networks" as the least formal entity with indistinct boundaries (Vilaplana 1998). Networks are defined as "an interconnected group of people linked to one another in a way that makes them capable of beneficial collaboration" (King 2011, p. 376). They "arise from and are sustained by the relationships between individuals over some shared concern, belief or value" (Lowndes et al. 1997 cited in Vilaplana 1998, p. 6). In relation to DRR, networks not only bring people together, but also support the organizations and infrastructure that enable actionable research (for example, the Clinical Research Network in the UK). The term network implies more than the sum of the actors and their links-networks are forms of social organization (Provan and Kenis 2008). Thus networks are holistic in nature.

There are many examples of established S\&T networks, partnerships, and platforms for DRR. Examples of global 
partnerships include the Global Volcano Model Network, ${ }^{1}$ the Global Flood Partnership, ${ }^{2}$ the Global Alliance of Disaster Research Institutes, ${ }^{3}$ the International Network for Government Science Advice, ${ }^{4}$ the Young Hydrologic Society, ${ }^{5}$ and even national networks such as the UK Alliance for Disaster Research. ${ }^{6}$ It is beyond the scope of this opinion piece to map out the different types of current S\&T networks for DRR. Our focus is instead upon understanding the value that networks may have and encouraging deeper insights into the role of S\&T networks for DRR. This mapping exercise and the development of a comprehensive database of S\&T networks for DRR needs to be done in order to evaluate existing S\&T networks in DRR and guide their future development.

While examining existing international science "partnerships" in DRR (for example, the International Decade for Disaster Risk Reduction), Carabine (2015) concludes that it is crucial to improve the existing evidence base and use of S\&T, especially when taking on board and coordinating a variety of stakeholders. The main contribution of the international science partnerships to DRR is through creating scientific evidence and promoting the use of S\&T for creation of evidence-based policy. We propose that a parallel can be drawn with the potential role of S\&T networks in DRR, especially at the science-policy interface. By acknowledging the complex nature of DRR, the Sendai Framework recognizes the need for collaborative action between key stakeholders (including policymakers, practitioners, and the S\&T community) from all regions and levels. Their collaboration will "identify knowledge gaps, co-design and co-produce knowledge, and make science more available and accessible to support DRR decision making on the ground" (Aitsi-Selmi et al. 2016, p. 4). In this sense, effective S\&T networks for DRR are inherently transdisciplinary.

The contribution of S\&T networks for DRR can go beyond mere informing of evidence-based policy. For instance, the collaboration between different S\&T networks can assist the implementation of the Sendai Framework, particularly by supporting monitoring and review of the Framework's targets (United Nations General Assembly 2016). S\&T networks can provide knowledge and resources to address the gaps identified in the assessment and monitoring of the Hyogo Framework 2005-2015, "which was generally admitted to be too weak and based on self-reporting or voluntary, self-initiated peer review"

\footnotetext{
${ }^{1} \mathrm{http}: / /$ globalvolcanomodel.org/.

2 http://gfp.jrc.ec.europa.eu/.

${ }^{3}$ http://gadri.net/.

${ }^{4}$ http://www.ingsa.org/.

5 https://younghs.com/.

${ }^{6}$ http://www.ukadr.org/.
}

(Mysiak et al. 2015, p. 2192). With the power to integrate climate change policy, DRR, and poverty reduction, S\&T networks also have the potential to work across the implementation of multisectoral international agendas such as the Sendai Framework, the Sustainable Development Goals, ${ }^{7}$ and the COP21 Agreement on Climate Change. ${ }^{8}$ Providing a shared platform of knowledge on disaster risk and mitigation can enhance the international commitment towards collaborative risk management plans.

\section{How Do We Benefit from Networks and What are the Challenges?}

To the best of our knowledge, there is a lack of published literature on the role, potential, and position of S\&T networks in the field of DRR. We propose that transferring lessons and associated learning from other fields can offer invaluable lessons for S\&T networks for DRR. Such crossfertilization can ultimately enhance a needed holistic approach for the implementation of the Sendai Framework. In order to gain an initial insight into the benefits of a network approach and the common challenges experienced, we conducted a literature review. It is important to emphasize that due to the lack of available literature on the role of S\&T networks in the context of DRR, the benefits and challenges of networks discussed in this review are based on the network and partnership literature in the wider context. However we acknowledge that these characteristics are potentially transferable to S\&T networks for DRR.

The results of the review (Table 1) provide evidence that networks can create an enabling environment for knowledge sharing, development, and technology transfer, and may address complex problems in a participatory manner at a low cost. Networks also have the potential to increase the prominence of issues of global concern (for example, climate change), and as such serve as a powerful tool in DRR. The potential benefits identified in Table 1 therefore form the basis of an enhanced role for S\&T networks in DRR. In order to inform DRR policy by delivering cutting-edge scientific and technological evidence, S\&T networks have a potential advantage over individual approaches in terms of coordination, shared resources, mutual learning, and exchange of knowledge and skills. Furthermore, they can capitalize on networks' inherent characteristics of fostering diversity and adaptiveness, as well as initiate a requirement for a form of facilitation that embraces and encourages innovation.

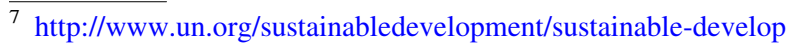
ment-goals/.

${ }^{8}$ http://unfccc.int/paris_agreement/items/9485.php.
} 
Table 1 Benefits and challenges of networks

\begin{tabular}{|c|c|c|}
\hline Themes & Benefits of networks & Challenges of networks \\
\hline \multirow[t]{3}{*}{ Coordination } & $\begin{array}{l}\text { Bring people and institutions together across sectors to reach } \\
\text { differing goals (Reinicke et al. 2000) }\end{array}$ & $\begin{array}{l}\text { Inability to coordinate and manage the network } \\
\text { (Plastrik et al. 2014) }\end{array}$ \\
\hline & $\begin{array}{l}\text { Pull diverse groups and address issues that no group can resolve by } \\
\text { itself (Witte et al. 2005) }\end{array}$ & $\begin{array}{l}\text { Institutionalization (that is, networks lose their } \\
\text { informal structure (Reinicke et al. 2000; Witte } \\
\text { et al. 2005) }\end{array}$ \\
\hline & $\begin{array}{l}\text { Avoid duplication of efforts (Caribbean Council for Science and } \\
\text { Technology 1999) }\end{array}$ & Members leaving (Kenis and Provan 2009) \\
\hline \multirow[t]{5}{*}{ Resources (in-kind) } & $\begin{array}{l}\text { Individual participants gain advantage (for example, through } \\
\text { developing long-term relations with at least some of the other } \\
\text { members) (Provan and Kenis 2008) }\end{array}$ & Underfunding (Carabine 2015) \\
\hline & $\begin{array}{l}\text { Each participating party brings different resources (Reinicke et al. } \\
\text { 2000) }\end{array}$ & \\
\hline & $\begin{array}{l}\text { Sharing best practices at low cost (Caribbean Council for Science } \\
\text { and Technology 1999; Reinicke et al. 2000; Provan and Kenis } \\
\text { 2008) }\end{array}$ & \\
\hline & Pool know-how (Witte et al. 2005) & \\
\hline & $\begin{array}{l}\text { Overcome high costs associated with research (Caribbean Council } \\
\text { for Science and Technology 1999) }\end{array}$ & \\
\hline \multirow[t]{7}{*}{$\begin{array}{l}\text { Learning, } \\
\text { knowledge and } \\
\text { skills exchange }\end{array}$} & $\begin{array}{l}\text { Networks are learning organizations based on a diversity of } \\
\text { participants; enhanced learning (Reinicke et al. 2000; Provan and } \\
\text { Kenis 2008) }\end{array}$ & \\
\hline & $\begin{array}{l}\text { Developing and sharing knowledge across levels, scales, and } \\
\text { disciplines (Reinicke et al. 2000; Witte et al. 2005) }\end{array}$ & \\
\hline & Awareness raising (Reinicke et al. 2000) & \\
\hline & $\begin{array}{l}\text { Influence the adoption of ideas, innovations, and behaviors (Scherer } \\
\text { and Cho 2003) }\end{array}$ & \\
\hline & $\begin{array}{l}\text { Building community capacity (Wagner and Leydesdorff 2005; } \\
\text { Provan and Kenis 2008) }\end{array}$ & \\
\hline & $\begin{array}{l}\text { Technology transfer (Caribbean Council for Science and } \\
\text { Technology 1999; Scherer and Cho 2003) }\end{array}$ & \\
\hline & Individual participants gain advantage (Provan and Kenis 2008) & \\
\hline \multirow[t]{3}{*}{ Facilitation } & $\begin{array}{l}\text { Create options that are more efficient, effective, and participatory } \\
\text { (Reinicke et al. 2000) }\end{array}$ & $\begin{array}{l}\text { Decreasing participation of members (Provan and } \\
\text { Kenis 2008) }\end{array}$ \\
\hline & $\begin{array}{l}\text { Create trust among participants and a forum for raising new issues } \\
\text { (Witte et al. 2005) }\end{array}$ & $\begin{array}{l}\text { Inability to facilitate through network (Plastrik } \\
\text { et al. 2014) }\end{array}$ \\
\hline & $\begin{array}{l}\text { Can serve as an implementation mechanism (for example, Global } \\
\text { Environmental Facility) (Reinicke et al. 2000) }\end{array}$ & \\
\hline \multirow[t]{2}{*}{ Diversity } & Strength in diversity, not uniformity (Witte et al. 2005) & \multirow{2}{*}{$\begin{array}{l}\text { Uniformity of members/lack of diversity of } \\
\text { representation (Sørensen and Torfing 2016) }\end{array}$} \\
\hline & $\begin{array}{l}\text { Use of knowledge and experience of multi-stakeholder participants } \\
\text { from different social, cultural, and political backgrounds (Witte } \\
\text { et al. 2005) }\end{array}$ & \\
\hline \multirow[t]{3}{*}{ Dynamic/adaptable } & Situational and opportunistic (Witte et al. 2005) & \multirow{3}{*}{$\begin{array}{l}\text { External pressure, for example, political pressure } \\
\text { (Witte et al. 2005) }\end{array}$} \\
\hline & $\begin{array}{l}\text { Networks are adaptable and flexible forms (Comfort 2005; Provan } \\
\text { and Kenis 2008) }\end{array}$ & \\
\hline & $\begin{array}{l}\text { Capacity to plan for and address complex problems (Provan and } \\
\text { Kenis 2008) }\end{array}$ & \\
\hline
\end{tabular}

Formulating, implementing, and managing any form of a network comes with challenges that can hinder that network's effectiveness. Table 1 demonstrates that networks should be aware of endogenous challenges, such as members leaving or reducing their degree of participation (for several reasons: for example, lack of internal legitimacy of the network, or the network is not living up to their expectations), and exogenous challenges, such as political pressure, or losing flexibility and becoming institutionalized (Provan and Kenis 2008). The nuance absent from this 
overview, however, is that many challenges present themselves in a mix of internal and external factors that compound to decrease network performance (Provan and Kenis 2008). One example of such a complex mixed challenge is funding, because funding is heavily dependent on its sources (whether internal or external) and the wider context of social, political, and economic disruption of the organization and its surrounding system.

\section{Conclusions}

Up-to-date research and evaluation regarding the application of S\&T networks in the field of DRR remains limited. We argue that this statement is especially valid when networks of interest are limited to S\&T networks, despite the fact that S\&T networks have the potential to contribute to the evidence base for policy, and support effective implementation, monitoring, and review of the Sendai Framework targets. Even though the international community is calling for the increased use of S\&T and networks in meeting the aspirations of Sendai Framework at all levels, the available research still appears to neglect these important aspects. Current practice is oriented towards a narrative that emphasizes the potential of S\&T for DRR and a collaborative approach delivered through networks. This short perspective shows that this narrative, however, is missing a true understanding of whether and how S\&T networks are currently performing, can mobilize and enable S\&T for DRR, and can identify what are the challenges experienced by existing DRR networks.

We need further research on how lessons identified from networks generally apply to S\&T networks specifically within the field of DRR. It is essential to define a good practice guidelines for creating a successful S\&T network and/or aligning existing networks, based on the understanding of how other networks have succeeded or failed at forming, governing, and funding their activities and to what extent these networks have met their goals. Development of a framework for the effective evaluation of networks would also be beneficial. In order to share the lessons and best practices of existing successful networks, and foster cooperation between existing initiatives, we propose the creation of a comprehensive database of S\&T networks for DRR. More knowledge is needed on how common challenges experienced in networks (for example, leveraging human capacity, governance, and funding) can be overcome. The robust, evidence-based good practice guidelines created will be pivotal to structuring and informing existing and future S\&T networks, as well as to establish the UNISDR Science and Technology Roadmap and, ultimately, contribute to meeting the targets of the Sendai Framework.

Acknowledgements The authors want to acknowledge Deltares, UNESCO-IHE Institute for Water Education, United Nations Major Group for Children and Youth, and Water Youth Network for organizing the Young Scientists in Disaster Risk Reduction event (Delft, The Netherlands, 12 May 2016), where the idea for this article was born. Also, the authors acknowledge anonymous reviewers for their valuable comments that improved the manuscript.

Open Access This article is distributed under the terms of the Creative Commons Attribution 4.0 International License (http://crea tivecommons.org/licenses/by/4.0/), which permits unrestricted use, distribution, and reproduction in any medium, provided you give appropriate credit to the original author(s) and the source, provide a link to the Creative Commons license, and indicate if changes were made.

\section{References}

Aitsi-Selmi, A., V. Murray, C. Wannous, C. Dickinson, D. Johnston, A. Kawasaki, A.-S. Stevance, and T. Yeung. 2016. Reflections on a Science and Technology agenda for 21 st century disaster risk reduction. International Journal of Disaster Risk Science 7(1): 1-29.

Assens, C., and A. Courie Lemeur. 2016. Introduction in networks governance, partnership management and coalitions federation. London: Palgrave Macmillan UK.

Carabine, E. 2015. Revitalising evidence-based policy for the Sendai Framework for Disaster Risk Reduction 2015-2030: Lessons from existing international science partnerships. PLOS Current Disasters. doi:10.1371/currents.dis. aaab45b2b4106307ae2168a485e03b8a.

Caribbean Council for Science and Technology. 1999. A study evaluating the effectiveness of science and technology networks operating in the subregion. http://www.cepal.org/publicaciones/ xml/5/10215/carg0589.pdf Accessed 15 Mar 2017.

Comfort, L.K. 2005. Risk, security, and disaster management. Annual Review of Political Science 8: 335-356.

Dickinson, C., A. Aitsi-Selmi, P. Basabe, C. Wannous, and V. Murray. 2016. Global community of disaster risk reduction scientists and decision makers endorse a Science and Technology Partnership to support the implementation of the Sendai Framework for Disaster Risk Reduction 2015-2030. International Journal of Disaster Risk Science 7(1): 108-109.

Himmelman, A.T. 1996. On the theory and practice of transformational collaboration: From social service to social justice. In Creating collaborative advantage, ed. C. Huxham, 20-43. London: Sage.

Kenis, P., and K. Provan. 2009. Towards an exogenous theory of public network performance. Public Administration 87(3): $440-456$.

King, R. 2011. Power and networks in worldwide knowledge coordination: The case of global science. Higher Education Policy 24(3): 359-376.

Lowndes, V., P. Nanton, A. McCabe, and C. Skelcher. 1997. Networks, partnerships and urban regeneration. Local Economy 11(4): 333-342.

Mysiak, J., S. Surminski, A. Thieken, R. Mechler, and J. Aerts. 2015. Brief communication: Sendai Framework for disaster risk reduction - success or warning sign for Paris? Natural Hazards and Earth System Sciences Discussions 3(6): 3955-3966. 
OECD (Organisation for Economic Co-operation and Development). 2007. Revised field of science and technology (FOS) classification in the Frascati manual. Directorate for Science, Technology and Industry, Committee for Scientific and Technological Policy. Working Party of National Experts on Science and Technology Indicators. https://www.oecd.org/science/inno/38235147.pdf. Accessed 25 Nov 2016.

Plastrik, P., M. Taylor, and J. Cleveland. 2014. Connecting to change the world: Harnessing the power of networks for social impact. Washington, DC: Island Press.

Provan, K.G., and P. Kenis. 2008. Modes of network governance: Structure, management, and effectiveness. Journal of Public Administration Research and Theory 18(2): 229-252.

Reinicke, W.H., F. Deng, J.M. Witte, T. Benner, B. Whitaker, and J. Gershman. 2000. Critical choices: The United Nations, networks and the future of global governance. Ottawa, Canada: International Development Research Centre.

Scherer, C.W., and H. Cho. 2003. A social network contagion theory of risk perception. Risk Analysis 23(2): 261-267.

Sørensen, E., and J. Torfing. 2016. Theories of democratic network governance. London: Palgrave Macmillan UK.

United Nations General Assembly. 2016. Report of the open-ended intergovernmental expert working group on indicators and terminology relating to disaster risk reduction. http://www. preventionweb.net/files/50683_oiewgreportenglish.pdf. Accessed 9 Mar 2017.

UNISDR (United Nations International Strategy for Disaster Reduction). 2015. Sendai Framework for Disaster Risk Reduction 2015-2030. Geneva: UNISDR.
UNISDR (United Nations International Strategy for Disaster Reduction). 2016. The Science and Technology Roadmap to support the implementation of the Sendai Framework for Disaster Risk Reduction 2015-2030. http://www.preventionweb.net/files/ 45270_unisdrscienceandtechnologyroadmap.pdf. Accessed 15 Nov 2016.

UNITAR (United Nations Institute for Training and Research). 2015. The special role of science and technology in the new DRR framework. http://www.unitar.org/special-role-technology-newdrr-framework. Accessed 9 Mar 2017.

UNMGCY (United Nations Major Group for Children and Youth). 2015. Young Scientists Platform on Disaster Risk Reduction. http://www.preventionweb.net/files/47816_47816con ceptnoteyoungscientistsplat.pdf. Accessed 15 Mar 2017.

Vilaplana, B. 1998. Partnerships and networks as new mechanisms towards sustainable urban regeneration. Working paper No. 1. London: University College London. http://www.bartlett.ucl.ac. uk/dpu/latest/publications/dpu-working-papers/WP_91.pdf. Accessed 20 Nov 2016.

Wagner, C., and L. Leydesdorff. 2005. Network structure, selforganization, and the growth of international collaboration in science. Research Policy 34(10): 1608-1618.

Witte, J., W. Reinicke, and T. Benner. 2005. Beyond multilateralism: Global public policy networks. In Challenges of globalisation: New trends in international politics and society, ed. A. Pfaller, and M. Lerch, 109-131. New Brunswick, NJ: Transaction Publishers. 